\title{
Clinical Significance and Oncogenic Activity of GRWDI Overexpression in the Development of Colon Carcinoma
}

This article was published in the following Dove Press journal: OncoTargets and Therapy

\author{
Xin Zhou $\mathbb{D}^{1, *}$ \\ Jin Shang ${ }^{2} *$ \\ Xing Liu', \\ Jin-Fu Zhuang (D' \\ Yuan-Feng Yang' \\ Yi-Yi Zhang' \\ Guo-Xian Guan (D) \\ 'Department of Colorectal Surgery, The \\ First Affiliated Hospital of Fujian Medical \\ University, Fuzhou, 350005, Fujian, \\ People's Republic of China; ${ }^{2}$ The First \\ Affiliated Hospital, School of Medicine, \\ Xiamen University, Xiamen, 36II02, \\ Fujian, People's Republic of China \\ *These authors contributed equally to \\ this work
}

\begin{abstract}
Objective: GRWD1 (glutamate-rich WD40 repeat containing 1) is a multifunctional protein involved in multiple cellular regulatory pathways, particularly those associated with cell growth control. GRWD1 is represented as a potential oncogene in several cancers, however, the function and mechanism of GRWD1 in the development of colon cancer are still unknown.
\end{abstract}

Materials and Methods: IHC was used to detect the expression of GRWD1 in colon carcinoma tissues. CCK-8, colony formation, and EdU were used to measure the cell proliferation after GRWD1 knockdown and overexpression. The distribution of the cell cycle was analyzed by flow cytometry. The effect of GRWD1 knockdown on migration and invasion was analyzed by wound healing and transwell assays.

Results: Overexpression of GRWD1 in colon carcinoma tissues was associated with pathological grading, tumor size, N stage, TNM stage, and poor survival. GRWD1 had high sensitivity and specificity in distinguishing colon cancer from noncancerous tissues, and might be served as an independent prognosis in colon carcinoma patients. Knockdown of GRWD1 significantly inhibited the cell proliferation and colony formation, and induced cell cycle arrest and more drug susceptibility, and suppressed the migration and invasion. GRWD1 exhibited these oncogenic activities might be associated with its regulation on the expression of PCNA and Ki67, Cyclin A2 and Cyclin B1, ABCC1 and GSTP1, MTA1 and MTA2.

Conclusion: GRWD1 may play an oncogenic activity in the development of colon carcinoma and its overexpression was associated with malignant characteristics and poor survival outcome of colon carcinoma. GRWD1 might be a potential target for future therapy.

Keywords: proliferation, cell cycle, drug susceptibility, migration and invasion, GRWD1, colon carcinoma

\section{Introduction}

Colorectal carcinoma (CRC) is the third commonly diagnosed cancer and one of the leading causes of cancer death. Besides, morbidity and mortality are both increasing in the most recent decade in many countries including China. ${ }^{1}$ Especially, colon carcinoma incidence is rising among young adults. According to the studies between 1975 and 2010, the incidence of young patients ( $<50$ years old) was increasing by years. ${ }^{2}$ The mortality rates were predicted based on this trend, in 2030, the incidences for patients 20 to 34 years and 35 to 49 years will increase by $27.7 \%$ and $46 \%$, respectively. ${ }^{3}$ Although early detection of colon cancer and
Correspondence: Guo-Xian Guan Department of Colorectal Surgery, The First Affiliated Hospital of Fujian Medical University, 20 Chazhong Road, Fuzhou, 350005, Fujian, People's Republic of China Tel +86l360959232l

Email fjxhggx@I63.com 
surgery increased survival among patients, the poor early diagnosis and high rates of metastasis have significantly decreased the 5 -year survival rates. ${ }^{4,5}$ Therefore, it is necessary to further investigate the pathogenesis of colon carcinoma so that we have to find some new strategies for diagnosis and treatment to reduce the mortality.

GRWD1 (glutamate-rich WD40 repeat containing 1), highly conserved throughout eukaryotes, is likely to be involved in ribosome biosynthesis. ${ }^{6}$ Previous studies suggested that p53 could be activated through the RPL11MDM2 axis. GRWD1 could negatively regulate the expression of p53 through inhibiting the interaction of RPL11 and MDM2. A recent study showed that GRWD1 could also inhibit p53 by directly binding to its DNAbinding domain. Based on these results, GRWD1 could be a potential oncogene. ${ }^{7-9}$

It has been confirmed that GRWD1 was highly expressed in non-small cell lung cancer (NSCLC) and related to poor differentiation and prognosis. ${ }^{10} \mathrm{PiHL}$, a transcriptional target of $\mathrm{p} 53$, played an important role in CRC cell proliferation by inducing p53 ubiquitination through promoting the complex formation of GRWD1 and RPL11. ${ }^{11}$ However, the expression and function of GRWD1 in colon carcinoma are still unknown. Here we show that the upregulation of GRWD1 promotes the development of colon carcinoma and predicts a poor prognosis.

\section{Materials and Methods}

\section{Tissue Samples and Clinical Data}

A tissue microarray (TMA) purchased from Shanghai Xin chao Biotech Co. Ltd was used for this study. The study was approved by the Medical Ethics Committee of The First Affiliated Hospital of Xiamen University in accordance with the ethical guidelines of the 1975 Declaration of Helsinki. This TMA contains 94 formalin-fixed and paraffin-embedded primary colon carcinoma specimens and 86 matched adjacent noncancerous colon specimens. The matched adjacent noncancerous tissues were obtained from a segment of the resected specimens that were $>5 \mathrm{~cm}$ away from the tumor. None of the patients received preoperative radiation or chemotherapy. The clinicopathological data were summarized in Table 2.

\section{Immunohistochemistry (IHC)}

$4 \mu \mathrm{m}$-thick sections of Paraffin-embedded tissues were dewaxed in xylene, then rehydrated and heated into $0.01 \mathrm{M}$ citrate buffer for $20 \mathrm{~min}$. The samples were quenched the endogenous peroxidase activity by $0.3 \%$ $\mathrm{H}_{2} \mathrm{O}_{2}$. After blocking with goat serum for $1 \mathrm{~h}$, samples were incubated with anti-GRWD1 antibody (1:500 dilution; HPA042643; Sigma, America) at $4^{\circ} \mathrm{C}$ overnight. The positive signals were visualized via the DAB kit (Maxin Bio, Fuzhou, China) and then scored. The scoring was assessed based on the percentage of positive cells and intensity of the staining in GRWD1. Staining intensity was scored as follows: -, 10\%; +, 10\%-25\%; ++, 26$50 \% ;+++,>50 \%$. All scores were subdivided into two categories: GRWD1 high expression $(++,+++)$ and low expression $(-,+)$. Scoring was performed by two independent individuals to avoid subjectivity.

\section{Cell Culture and Transfection}

The human CRC cell lines RKO and SW480 were purchased from the Cell Bank of Type Culture Collection of Chinese Academy of Sciences (Shanghai, China). Cells were cultured at $37^{\circ} \mathrm{C}$ with $5 \% \mathrm{CO}_{2}$ in DMEM medium, supplemented with $10 \%$ FBS (Peakserum, US) and $100 \mathrm{U} / \mathrm{mL}$ penicillin. Plasmids of knockdown or overexpression of GRWD1 were constructed by Public Protein/Plasmid Library. HEK293T cells were transfected by the resulting lentiviral vector and packing plasmids with Lipofectamine 2000 (Invitrogen). Medium was replaced after $8 \mathrm{~h}$, later supernatants were collected and filtered after $48 \mathrm{~h}$. RKO and SW480 cells were infected by viral supernatant and selected by puromycin.

\section{Western Blot Analysis}

Cells were collected and lysed with ice-cold lysis buffer, the extractives were centrifuged and supernatant was diluted 1:4 with protein loading buffer. $10 \mu \mathrm{g}$ of proteins were separated by SDS-PAGE and transferred to PVDF membranes. Following blocking with $5 \%$ nonfat milk at room temperature for $1 \mathrm{~h}$, membranes were incubated with primary antibodies at $4{ }^{\circ} \mathrm{C}$ overnight. After washing with PBST for 3 times, the membranes were incubated with the horseradish peroxidase-conjugated secondary antibodies at room temperature for $1 \mathrm{~h}$. Finally, an enhanced chemiluminescence system was used to detect the signals. The primary antibody GRWD1 was purchased from Sigma-Aldrich, $\alpha$ actinin was obtained from Proteintech.

\section{Cell Proliferation Assay and Drug Susceptibility Assay}

CCK8 assay (MCE) was used to detect the cell proliferation and cell survival after drug treatment. Cells were 
seeded with a density of $5 \times 10^{3} /$ well in 96 -well plates and cultured for a certain period time. $10 \mu \mathrm{L}$ CCK- 8 reagent was added into each well and incubated for $3 \mathrm{~h}$.

\section{Xenograft Nude Mouse Model}

All experimental procedures involving animals were conducted in accordance with animal protocols of the Laboratory Animal Center of Xiamen University, which were approved by the Animal Ethics Committee of Xiamen University. 4-6 weeks old Balb/c nude mice were separated randomly into two groups including control group and the GRWD1 knockdown group. $1 \times 10^{7}$ cells were subcutaneously injected into the right side of each mouse. The tumor sizes were measured every two days. All mice were euthanized on the 19th day and tumors were dissected.

\section{Colony Formation Assay}

RKO and SW480 cell lines were seeded on 6-well plates with 500 cells/well, respectively. Cells were cultured for two weeks with $5 \% \mathrm{CO} 2$ at $37^{\circ} \mathrm{C}$, then were treated with methanol for 10 minutes and stained with crystal violet for 15 minutes. The cell colonies were photographed under the microscope.

\section{EdU Incorporation Assay}

EdU assay (RiboBio, China) was used to measure cell proliferation. EdU is an analog of thymidine, it could replace thymidine to insert in synthetic DNA molecule during DNA duplicate phase. Briefly, cells were seeded at a density of $1 \times 10^{4} /$ well onto 96 -well plates, after cultured for $24 \mathrm{~h}$, cells were treated with $50 \mu \mathrm{M}$ EdU for $2 \mathrm{~h}$ with $5 \% \mathrm{CO} 2$ at $37^{\circ} \mathrm{C}$. Then, cells were washed with PBS twice to remove residual EdU and fixed with $4 \%$ formaldehyde for $30 \mathrm{~min}$. PBS with $0.5 \%$ Triton X-100 was used to permeate cells. Next, cells were treated with $1 \times$ Apollo $^{\circledR}$ fluorochrome for $30 \mathrm{~min}$ at a dark place. After that, each well was added with DAPI and $1 \times$ Hoechst 3342 reaction cocktail. Results were observed with a fluorescence microscope.

\section{Cell Cycle Analysis}

RKO and SW480 cells were treated with serum-free medium for $24 \mathrm{~h}$, then cells were softly collected and fixed with cold $70 \%$ ethanol at $4^{\circ} \mathrm{C}$ overnight. After that, cells were washed in cold PBS twice, and then resuspended in Cell Staining Buffer containing $2.5 \mu \mathrm{g} / \mathrm{mL}$ propidium iodide solution and $100 \mu \mathrm{g} / \mathrm{mL}$ RNase for 30 minutes at $37^{\circ} \mathrm{C}_{\circ}$
DNA content were analyzed by Flow Cytometry. The percentage of cells at each cell cycle phase was analyzed using the FlowJo software.

\section{Migration and Invasion Assays}

Wound-healing assay and transwell assay were used to measure the activities of migration and invasion. For wound-healing assay, SW480 and RKO cells were seeded into $35-\mathrm{mm}$ dishes and cultured for $24 \mathrm{~h}$ to $95 \%$ confluence. $200 \mu \mathrm{L}$ pipette tip was used to scratch the monolayer and the well was washed with PBS for three times to wipe off the detached cells. After that, cells were cultured with DMEM medium containing 1\% FBS. The same vision was captured under the microscope at $0 \mathrm{~h}$ and $48 \mathrm{~h}$. For transwell assay, Corning ${ }^{\circledR}$ BioCoat $^{\mathrm{TM}}$ Matrigel $^{\circledR}$ Invasion Chambers with $8.0 \mu \mathrm{m}$ PET Membrane were used according to the manufacturer's instruction. SW480 and RKO cells were seeded in the upper chamber with a serum-free medium. The lower chamber was supplemented with DMEM containing $10 \%$ FBS. After $48 \mathrm{~h}$, invaded cells were stained with crystal violet and counted. The migration assay was performed without Matrigel and other procedures were the same with invasion assay.

\section{Statistical Analysis}

SPSS 16.0 statistic software (SPSS Inc., Chicago, IL, United States) was used to analyze all data. All survival rate was analyzed by the Kaplan-Meier method using a long-rank test. Student's $t$-test was employed to compare the differences between the two groups. The $X^{2}$ was used to analyze the relationship between GRWD1 expression and clinical features. The value of $P<0.05$ was considered statistically significant.

\section{Results}

\section{Overexpression of GRWDI in Colon Cancer Tissues}

Evaluation from the online GEPIA database indicated that GRWD1 mRNA was widely expressed in many cancer tissues, but it was significantly highly expressed in COAD tissues compared with normal tissues $(P<0.05)$ (Figure 1A). In order to confirm the expression of GRWD1 in the colon cancer tissues, IHC was applied to detect the GRWD1 protein level in clinical colon cancer tissues and noncancerous tissues. The representative $\mathrm{H} \& \mathrm{E}$ staining images of noncancerous tissue and colon cancer tissue were shown in Figure 1B. IHC analysis showed that GRWD1 protein was weakly expressed in 
noncancerous tissues, while markedly expressed in the nucleus of colon cancer tissues (Figure 1C). To further investigate the expression of GRWD1 protein, the staining intensity was separated into four different grades including negative expression (-), weakly positive $(+)$, moderately positive $(2+)$, and highly positive (3+) (Figure 1D). The results from Table 1 showed that the rate of high expression $(2+, 3+)$ of GRWD1 in colon cancer tissues was $58.6 \%$, which was significantly

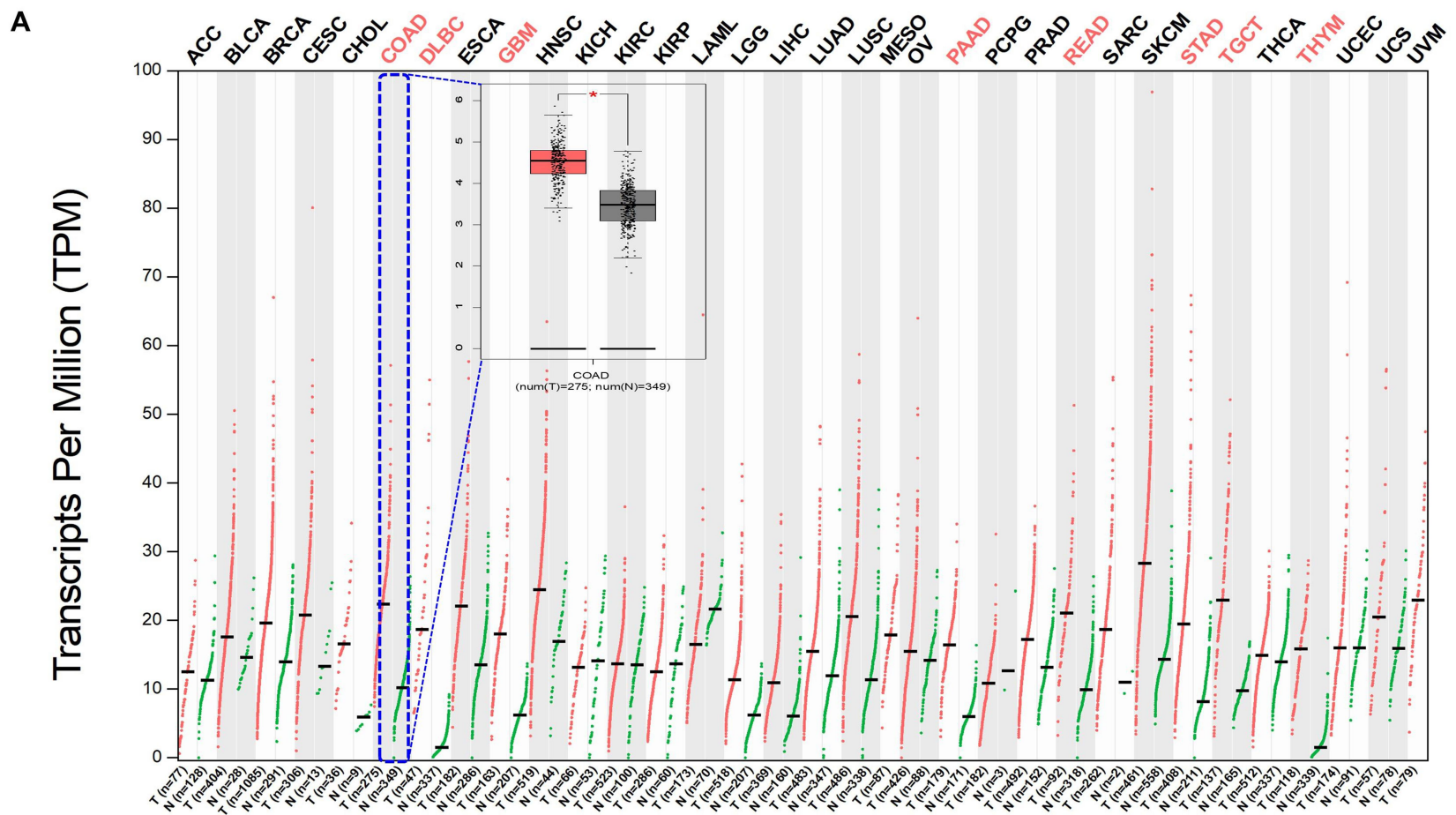

$\mathbf{B}$

\section{C}

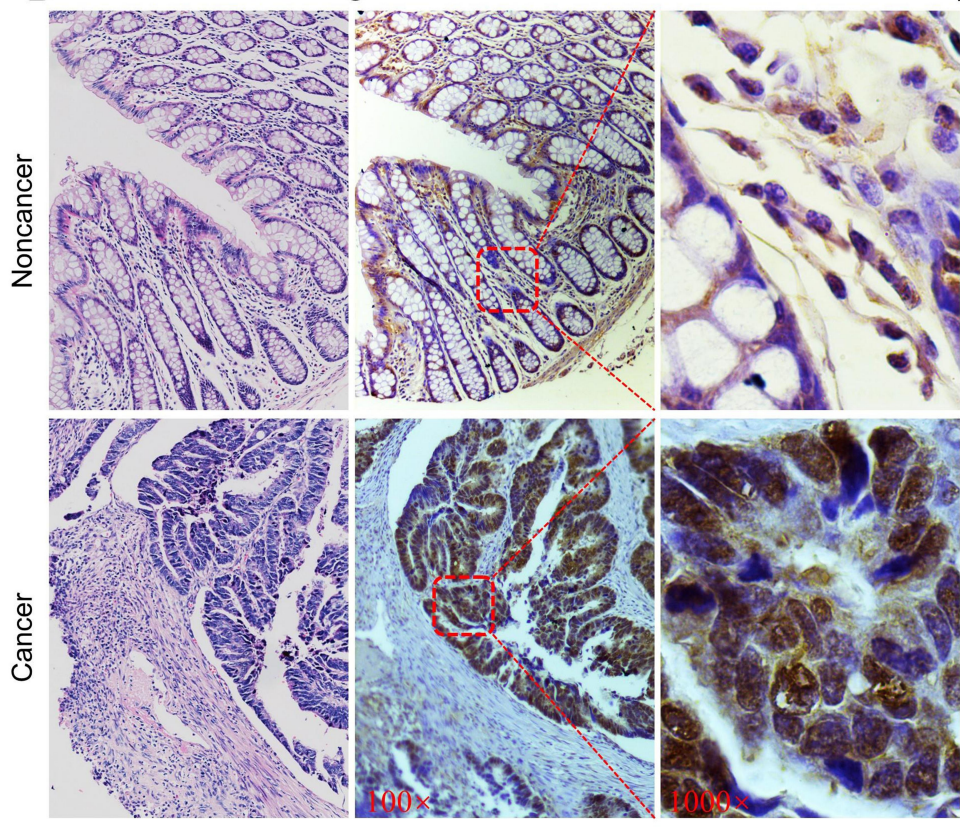

D

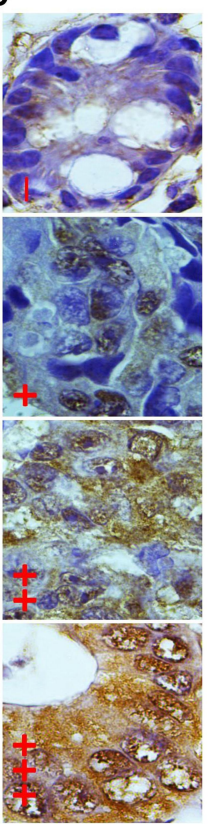

E
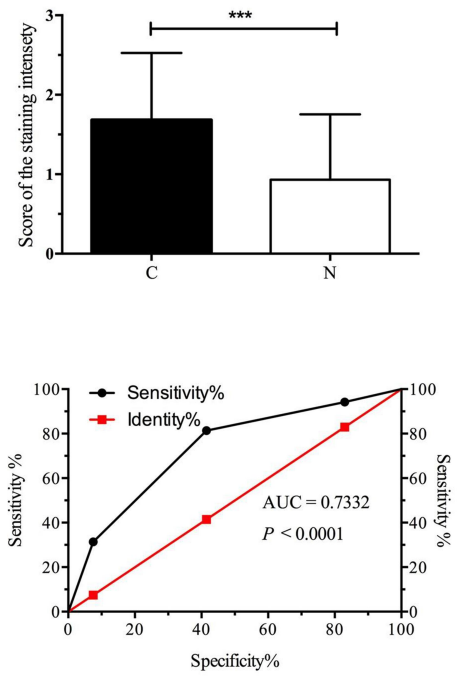

Figure I Expression levels of GRWDI in human cancers from online database and clinical colon cancer samples. (A) The red font for each cancer indicates the mRNA levels of GRWDI in tumor tissues (T) was significantly higher than noncancerous tissues (N), including colon adenocarcinoma (COAD). In the box plot, the red box indicates COAD samples $(n=275)$ and the grey box indicates normal samples $(n=349)$, $* P<0.05$. All these data were obtained from the GEPIA database. (B) Representative images for H\&E indicated noncancerous tissue (upper) and cancer tissue (bottom). (C) Comparison of GRWDI in noncancerous and cancer tissues via IHC staining (right, I00 $\times$; left, I000 $\times$ ). (D) IHC staining of GRWDI was sorted into four grades $(-,+,++,+++)$. (E) Semiquantitative analysis of GRWDI expression in noncancerous (N) and cancer tissues $(\mathbf{C})$ (the upper one, $* * * P<$ $0.00 \mathrm{I})$. Receiver operating characteristic (ROC) curve was plotted by sensitivity and specificity for GRWDI IHC staining score (the bottom one, AUC $=0.7332, P<0.000 \mathrm{I})$. 
Table I Expression of GRWDI Protein in Different Colon Tissues

\begin{tabular}{|l|l|c|c|c|c|c|c|}
\hline \multirow{2}{*}{ Tissue Type } & \multirow{2}{*}{$\mathbf{N}$} & \multicolumn{5}{|c|}{ GRWDI Staining Grades } & \multirow{2}{*}{$\boldsymbol{X}^{\mathbf{2}}$} \\
\cline { 3 - 6 } & & - & $\mathbf{I +}$ & $\mathbf{2 +}$ & $\mathbf{3}$ & \\
\hline Cancer (C) & 94 & $7(7.4 \%)$ & $32(34.0 \%)$ & $39(41.6 \%)$ & $16(17.0 \%)$ & 34.58 \\
Noncancer (N) & 86 & $27(31.3 \%)$ & $43(50.0 \%)$ & $12(14.0 \%)$ & $4(4.7 \%)$ & $<0.0001$ \\
\hline
\end{tabular}

higher than noncancerous tissues with $18.7 \%$. The histogram of the score also showed staining intensity of GRWD1 in colon cancer tissues was pretty higher than that of noncancerous tissues (Figure 1E, upper). In addition, we assessed the sensitivity and specificity of GRWD1 expression to discriminate cancer tissues from noncancerous tissues. The value of area under the curve (AUC) was $0.7332(95 \% \mathrm{CI}=0.6596$ to $0.8067, P<0.0001$ ) (Figure 1E, bottom), and the sensitivity was $82.97 \%$ and the specificity was $94.19 \%$, which presented that GRWD1 had high sensitivity and specificity in distinguishing colon cancer from noncancerous tissues.

\section{Clinical Significance of GRWDI Overexpression in Colon Carcinoma}

\section{Patients}

To explore the clinical significance of GRWD1 overexpression in colon carcinoma patients, the associations between GRWD1 expression level and clinical pathological factors were analyzed in Table 2 . The analysis revealed a marked association between GRWD1 overexpression with pathological grading, tumor size, $\mathrm{N}$ stage and TNM stage $(P<0.05)$. However, the correlation between GRWD1 overexpression and patients' age, gender, T category was not found $(P>0.05)$. These results suggest that GRWD1 overexpression might be served as a predictor for the progression of colon carcinoma patients.

\section{The Prognostic Value of GRWDI Overexpression in Colon Carcinoma}

\section{Patients}

Firstly, A survival analysis was performed using data from GEPIA database, but the Kaplan-Meier survival curves and Log rank test demonstrated that patients with overexpression of GRWD1 had no significant association with overall survival (OS) of all patients $(P>0.05)$. However, data from clinical colon carcinoma samples indicated that patients with overexpression of GRWD1 had a shorter OS rate than low expression $(P<0.05)$ (Figure $2 \mathrm{~A})$. Besides, the OS of colon patients with GRWD1 overexpression is poor both in clinical stage (III-IV) and clinical stage (II) $(P<0.05)$ (Figure
2B). Furthermore, Univariate Cox regression analysis showed that pathological differentiation, tumor size, clinical stage, lymph node metastasis, and GRWD1 expression were significantly associated with OS $(P<0.05)$. Pathological differentiation, clinical stage, lymph node metastasis, and GRWD1 expression were finally confirmed to be independent factors with prognostic value for OS in patients with colon carcinoma via Multivariate Cox analysis $(P<0.05)$

Table 2 Associations Between GRWDI and Clinicopathological Factors of Colon Carcinoma Patients

\begin{tabular}{|c|c|c|c|c|c|}
\hline \multirow[t]{2}{*}{ Variables } & \multirow[t]{2}{*}{$\mathbf{N}$} & \multicolumn{2}{|c|}{ GRWDI } & \multirow[t]{2}{*}{$x^{2}$} & \multirow[t]{2}{*}{$P$} \\
\hline & & Low & High & & \\
\hline Age & & & & 0.0307 & 0.8608 \\
\hline$<60$ & 28 & 12 & 16 & & \\
\hline$\geq 60$ & 66 & 27 & 39 & & \\
\hline Gender & & & & 0.2605 & 0.6495 \\
\hline Female & 46 & 18 & 28 & & \\
\hline Male & 48 & 21 & 27 & & \\
\hline Pathological grading & & & & 14.26 & $0.0008 *$ \\
\hline I, I-II & 19 & 15 & 4 & & \\
\hline II & 60 & 18 & 42 & & \\
\hline II-III, III, IV & 15 & 6 & 9 & & \\
\hline Tumor size & & & & 17.72 & $0.0001 *$ \\
\hline$d<4$ & 29 & 18 & 11 & & \\
\hline $4 \leq d<6$ & 36 & 18 & 18 & & \\
\hline$d \geq 6$ & 29 & 3 & 26 & & \\
\hline $\mathrm{T}$ category & & & & 1.300 & 0.5220 \\
\hline $\mathrm{TI} / 2$ & 11 & 3 & 8 & & \\
\hline T3 & 51 & 21 & 30 & & \\
\hline $\mathrm{T} 4$ & 32 & 15 & 17 & & \\
\hline $\mathrm{N}$ stage & & & & 6.593 & $0.0102 *$ \\
\hline No & 60 & 19 & 41 & & \\
\hline $\mathrm{NI}$ & 34 & 20 & 14 & & \\
\hline TNM stage (AJCC) & & & & 6.824 & $0.0330 *$ \\
\hline Stage I & 10 & 3 & 7 & & \\
\hline Stage II & 48 & 15 & 33 & & \\
\hline Stage III-IV & 36 & 21 & 15 & & \\
\hline
\end{tabular}

Note: *Indicates statistical significance.

Abbreviations: W, well differentiation; $M$, moderately differentiation; P, poorly differentiation. 
A

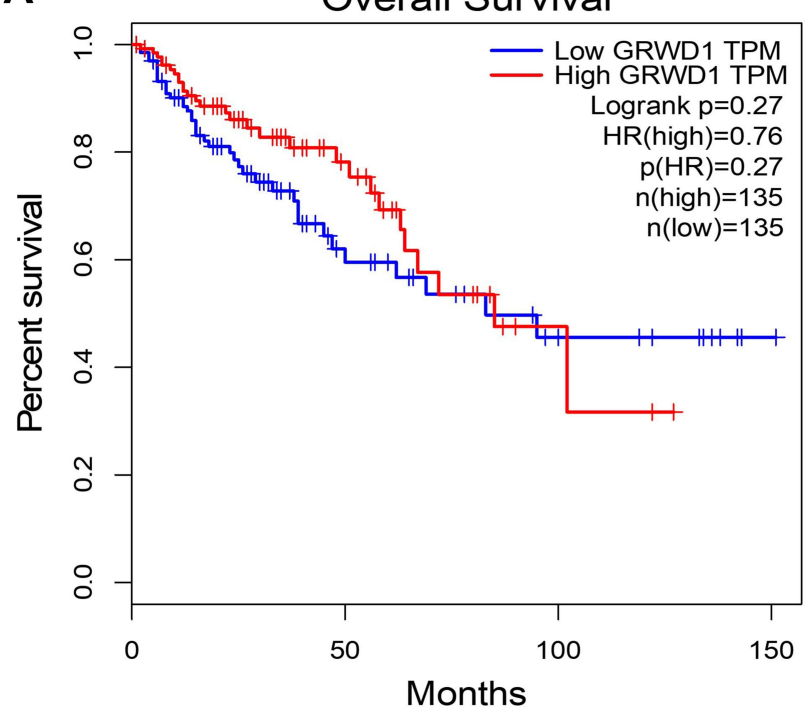

B Clinical stage III-IV

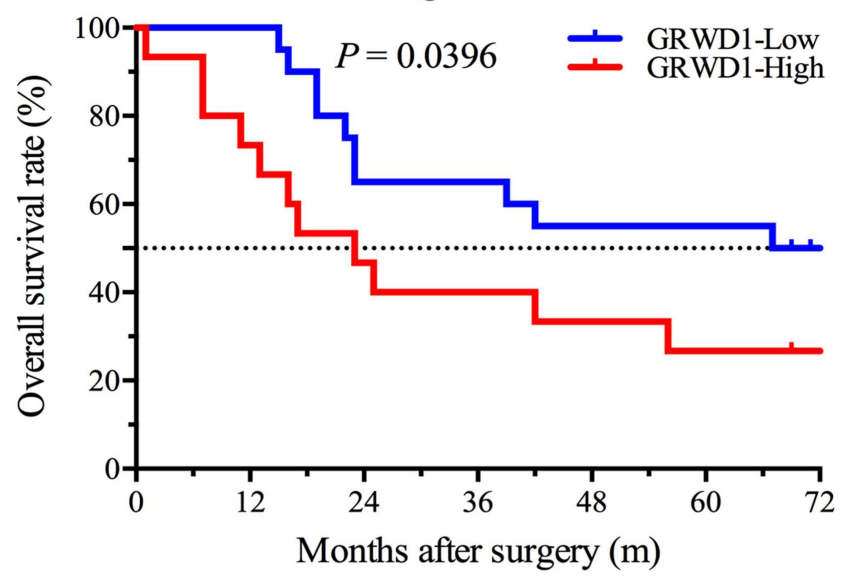

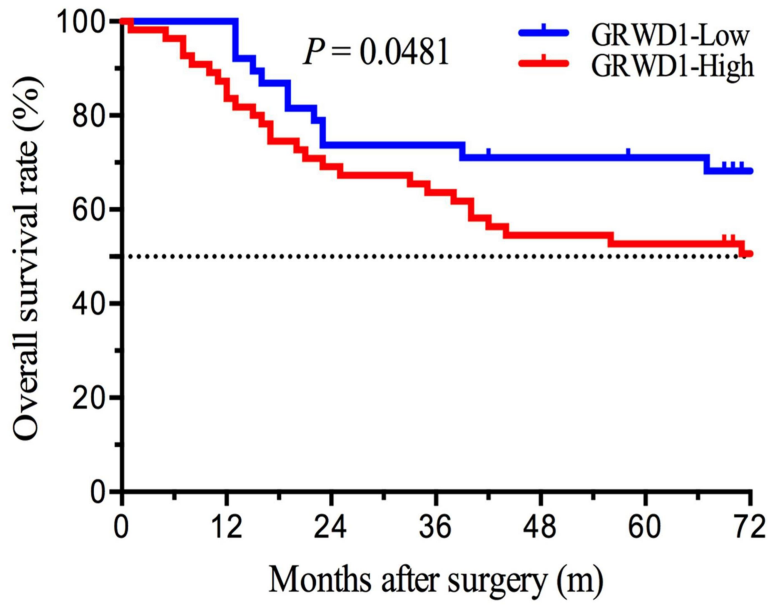

Clinical stage II

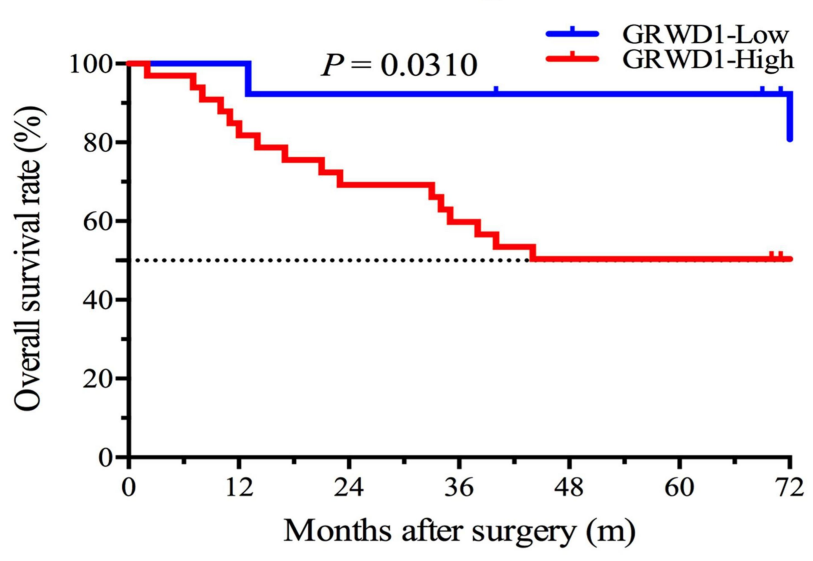

C

Pathlogical differentiation

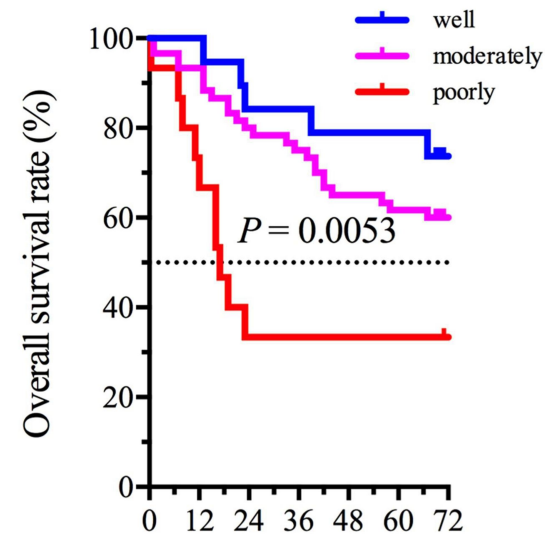

Months after surgery (m)
Clinical stage

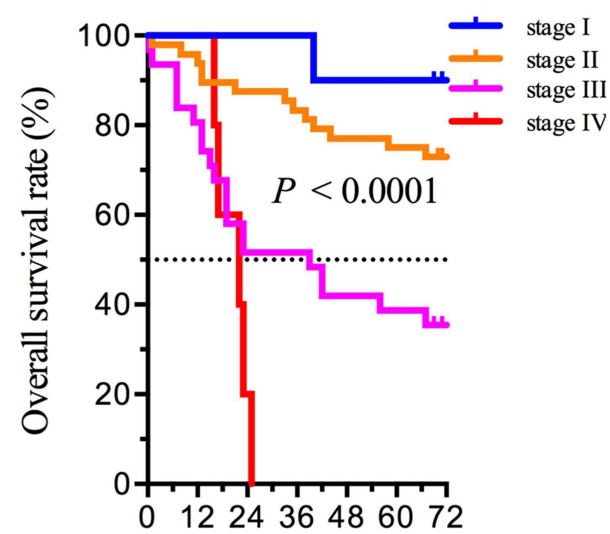

Months after surgery (m)
Lymph node metastasis

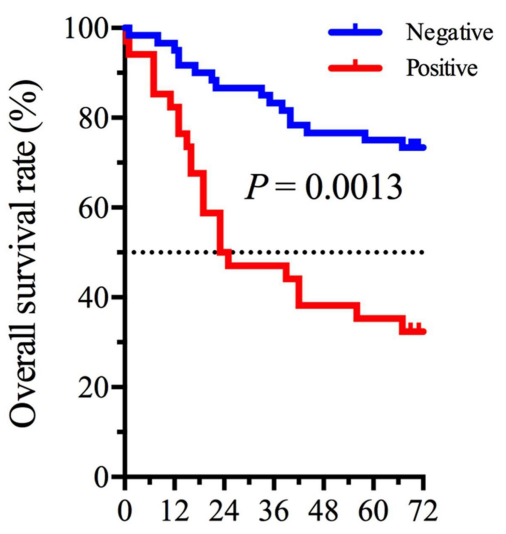

Months after surgery (m)

Figure 2 The relationship between GRWDI expression and overall survival (OS) in colon cancer patients. (A) Kaplan-Meier overall survival curve plotting relation between GRWDI expression and OS in colon cancer patients. Data of right one is from GEPIA database $(n=270, P=0.27)$, and the left one is from clinical data $(n=94, P=0.048 I)$. (B) The relations between GRWDI expression and OS were accessed in different sub-groups of clinical stage III-IV (left, $n=46, P=0.0396)$ and clinical stage II (right, $n=$ $36, P=0.0310)$ according to TNM stage. (C) OS analysis in colon cancer patients for pathological differentiation (left, $n=94, P=0.0053$ ), clinical-stage (middle, $n=94, P<$ $0.000 \mathrm{I}$ ), and lymph node metastasis (right, $n=94, P=0.0013$ ). The log-rank was used to calculate $P$ values. 
(Table 3). Kaplan-Meier survival curves confirmed that pathological differentiation, clinical stage, and lymph node metastasis were significantly associated with poor OS $(P<$ 0.05) (Figure 2C). These results indicated that GRWD1 overexpression predicted a poor prognosis of colon carcinoma patients.

\section{Knockdown of GRWDI Inhibits the Proliferation of Colon Cancer Cells}

To explore the functions of GRWD1 on colon cancer cells, the cell models of stable GRWD1 knockdown and overexpression were established, separately. The Western blot analyses of GRWD1 protein expression were presented in Figure 3A and B. The results of cell proliferation detected by CCK 8 assays showed that GRWD1 knockdown inhibited cell growth compared with control groups in both RKO and SW480 cells (Figure 3C). Conversely, the proliferation of both RKO and SW480 cells was enhanced after GRWD1 overexpression (Figure 3D). We also established the nude mouse model to verify the effect of GRWD1 on proliferation in vivo, the results showed that knockdown of GRWD1 inhibited tumor growth. The tumor weight of the GRWD1 knockdown group was much lower than the control group (Figure 3E).

Next, colony formation assays were used to detect the in-vitro tumorigenesis in RKO and SW480 cells. The results showed that knockdown of GRWD1 could significantly inhibit the colony formation both of RKO and SW480 cells (Figure 4A). Furthermore, EdU assay was performed to measure DNA synthesis, which could also represent the proliferative ability of cells. The results showed a remarkable decrease in the numbers of EdUpositive cells in shGRWD1 group compared with shCtrl group (Figure 4B).

These findings indicated that GRWD1 knockdown could significantly inhibit the proliferation of colon cancer cells in vitro and in vivo.

\section{Knockdown of GRWDI Induces GI Phase Cell Cycle Arrest}

Cell cycle disorder is one of the malignant characteristics in the development of colon carcinoma. ${ }^{12}$ Results from flow cytometry showed that GRWD1 knockdown inhibited cell cycle progression and caused the G1 phase distribution to increase from $40.12 \pm 1.02 \%$ to $56.89 \pm$ $1.17 \%(P<0.05)$, and it caused a slightly decreasing number of cells in $\mathrm{S}$ and $\mathrm{G} 2 / \mathrm{M}$ phase compared with control group in RKO cells (Figure 4C). In addition, GRWD1 knockdown also increased the G1 phase distribution from $41.31 \pm 1.18 \%$ to $55.36 \pm 0.91 \%(P<0.05)$, whereas the phase of $\mathrm{S}$ and $\mathrm{G} 2 / \mathrm{M}$ were decreased (Figure 4D). Similar results from RKO and SW480 cells indicated that GRWD1 played a key role in the procession of colon cancer cell cycle.

Table 3 Cox Model Analysis of Prognostic Factors and GRWDI on Overall Survival

\begin{tabular}{|l|l|l|}
\hline Variables & HR (95\% CI) & $P$ \\
\hline Univariate & $1.764(I .172-2.02 I)$ & 0.073 \\
\hline Age (<60 vs $\geq 60)$ & $0.927(0.256-1.653)$ & 0.162 \\
Gender (female vs male) & $2.102(I .213-2.972)$ & $0.03 I^{*}$ \\
Pathological grading (I, I-II vs II vs II-III, III, IV) & $1.817(I .29 I-2.65 I)$ & $0.039^{*}$ \\
Tumor size (d < 4 vs 4 $\leq$ d <6 vs d $\geq 6)$ & $0.362(0.162-0.932)$ & $0.4 I 2$ \\
T category (TI/2 vs T3/4) & $2.317(I .583-3.192)$ & $0.023^{*}$ \\
N stage (NO vs NI) & $3.572(I .582-9.382)$ & $0.009^{*}$ \\
TNM stage (TI/2 vs T3 vs T4) & $1.836(I .027-2.68 I)$ & $0.018^{*}$ \\
GRWDI (low vs high) & & \\
\hline Multivariate & $1.738(I .219-2.7 I 2)$ & $0.018^{*}$ \\
\hline Pathological grading (I, I-II vs II vs II-III, III, IV) & $1.932(I .317-3.0 I 8)$ & $0.042^{*}$ \\
N stage (NO vs NI) & $2.64 I(I .376-3.972)$ & $0.014^{*}$ \\
TNM stage (stage I vs II vs III vs IV) & $1.526(I .023-2.07 I)$ & $0.02 I^{*}$ \\
\hline GRWDI (low vs high) & & \\
\hline
\end{tabular}

Note: *Indicates statistical significance.

Abbreviations: $\mathrm{HR}$, hazard ratio; $\mathrm{Cl}$, confidence interval. 
A

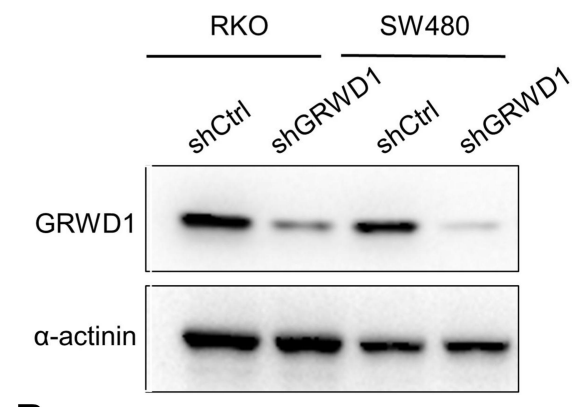

B

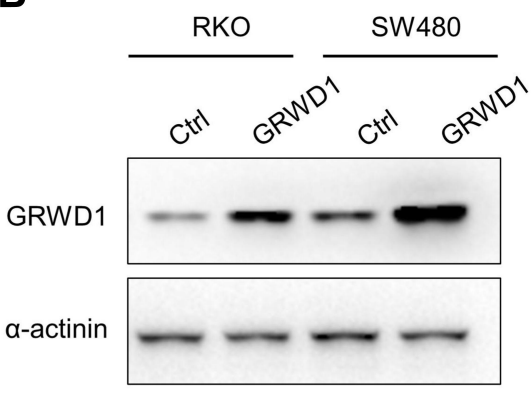

E

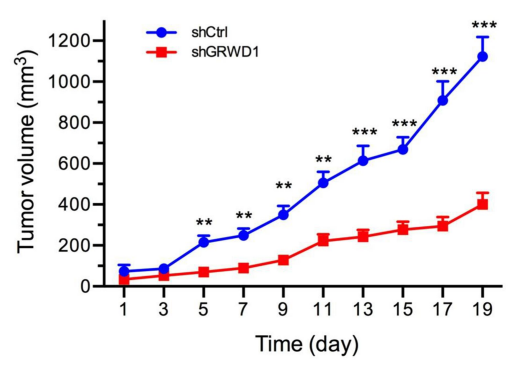

C

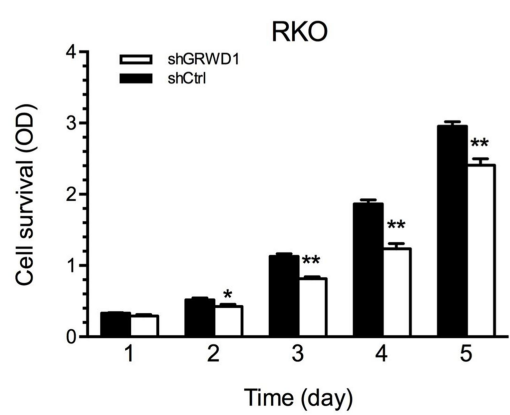

SW480
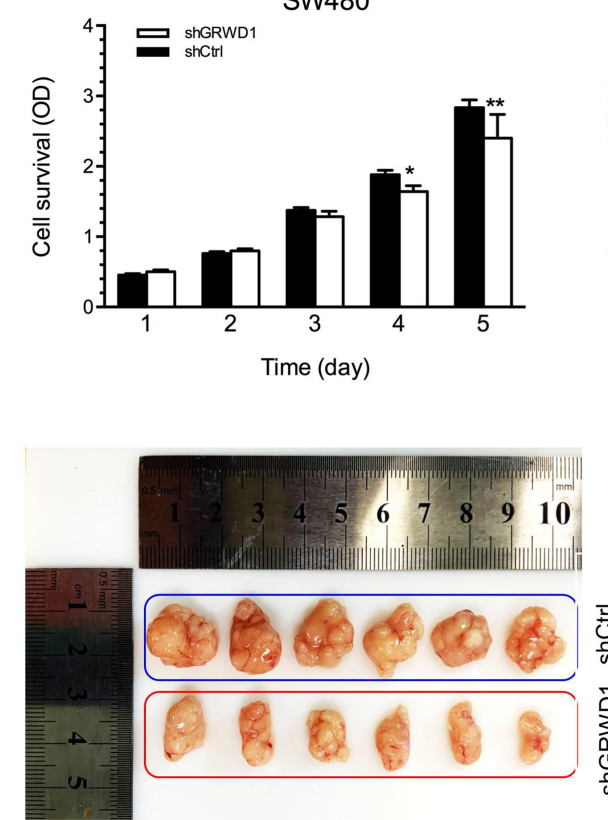

D
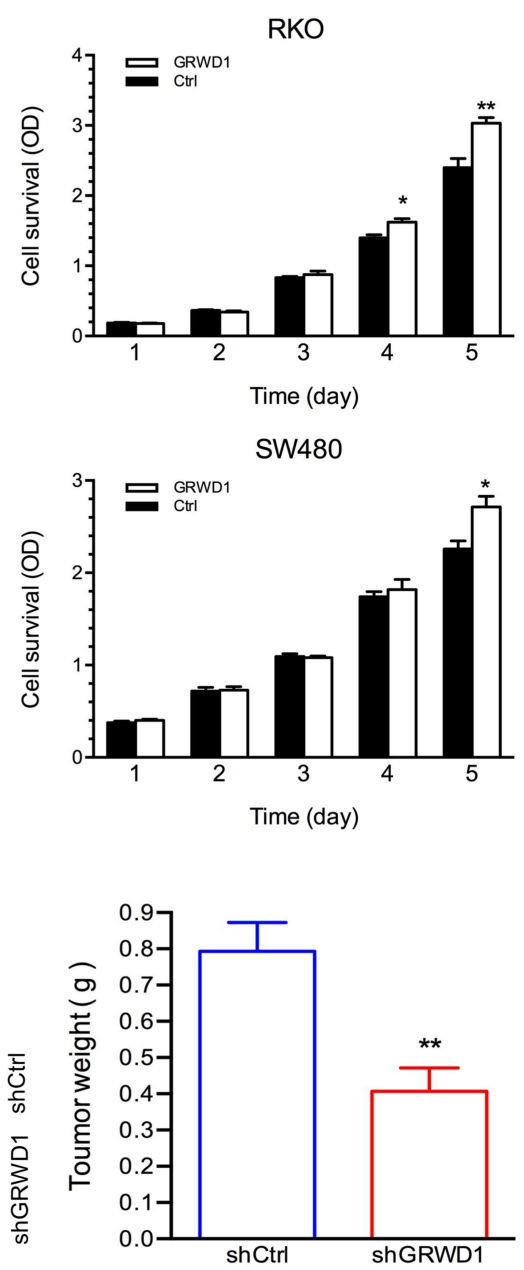

Figure 3 Effect of GRWDI on colon cancer cell proliferation in vitro and in vivo. (A and B) The protein levels of GRWDI knockdown and overexpression in RKO and SW480 cells. (C and D) The proliferation of RKO and SW480 cells detected by CCK8 analysis after GRWDI knockdown or overexpression. (E) Effect of GRWDI knockdown in vivo. Comparison of tumor growth (left), dissected tumors (middle) and tumor weight (right) in control and GRWDI knockdown groups. Data were expressed as mean \pm SD from three independent experiments. $* P<0.05 ; * * P<0.01$; $* * * P<0.001$.

\section{Knockdown of GRWDI Enhances Drug Susceptibility of Colon Cancer Cells}

Resistance to chemotherapy is a main obstacle in the tumor clinical therapy including colon carcinoma. ${ }^{13}$ To further investigate whether GRWD1 knockdown affected drug susceptibility in colon cancer cells, CCK8 assays were performed to detect drug susceptibility of RKO and SW480 cells to three common chemotherapy drugs including LOHP, CDDP and 5-FU after GRWD1 knockdown. As shown in Figure $5 \mathrm{~A}-\mathrm{C}$, the sensitivity to LOHP, CDDP, and 5-FU was increased after GRWD1 knockdown in both SW480 cells and RKO cells, compared with control groups. The results suggested that GRWD1 overexpression might contribute to the drug resistance of colon cancer cells.

\section{Knockdown of GRWDI Suppresses Migration and Invasion of Colon Cancer Cells}

In the clinical data analysis, it indicated that GRWD1 overexpression was associated with lymph node metastasis of colon carcinoma. Therefore, we detected the effect of GRWD1 knockdown on the migration and invasion by wound-healing assay and transwell assay. As shown in Figure 6A, the healing ability of RKO and SW480 cells was impaired after GRWD1 knockdown. Furthermore, transwell assays indicated that the migration and invasion activities of GRWD1 knockdown group cells were markedly decreased compared to the control group cells in both RKO (Figure 6B) and SW480 (Figure 6C) $(P<0.001)$. These two results suggested that GRWD1 played a vital 
A

RKO

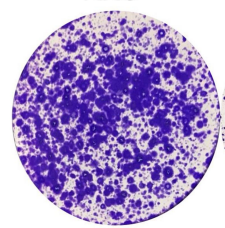

shGRWD1

B

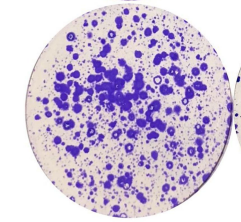

Hoechst
SW480

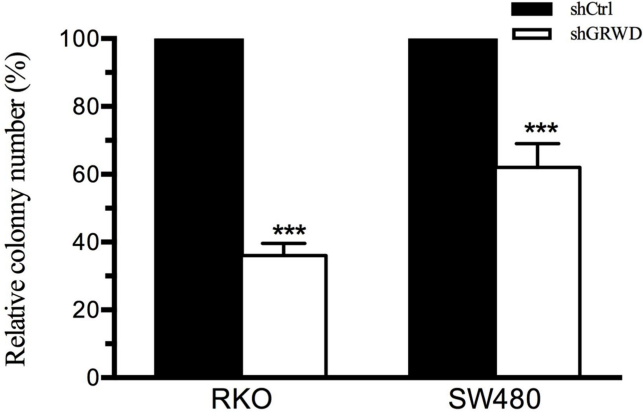

EdU
Overlay

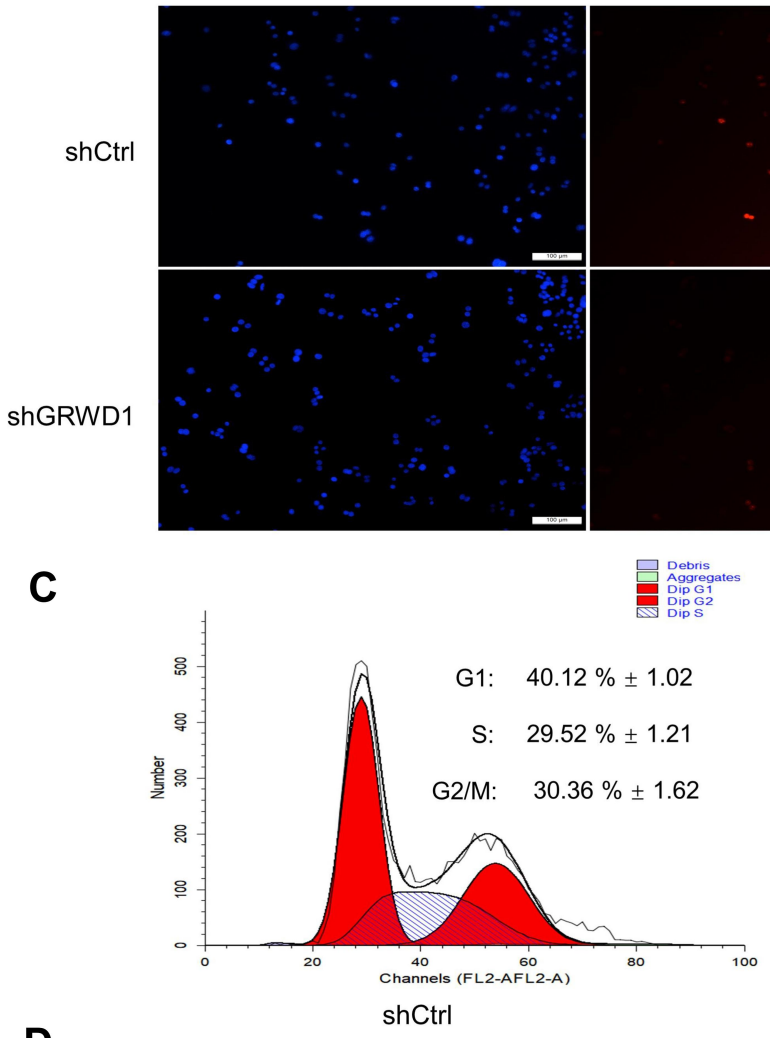

D
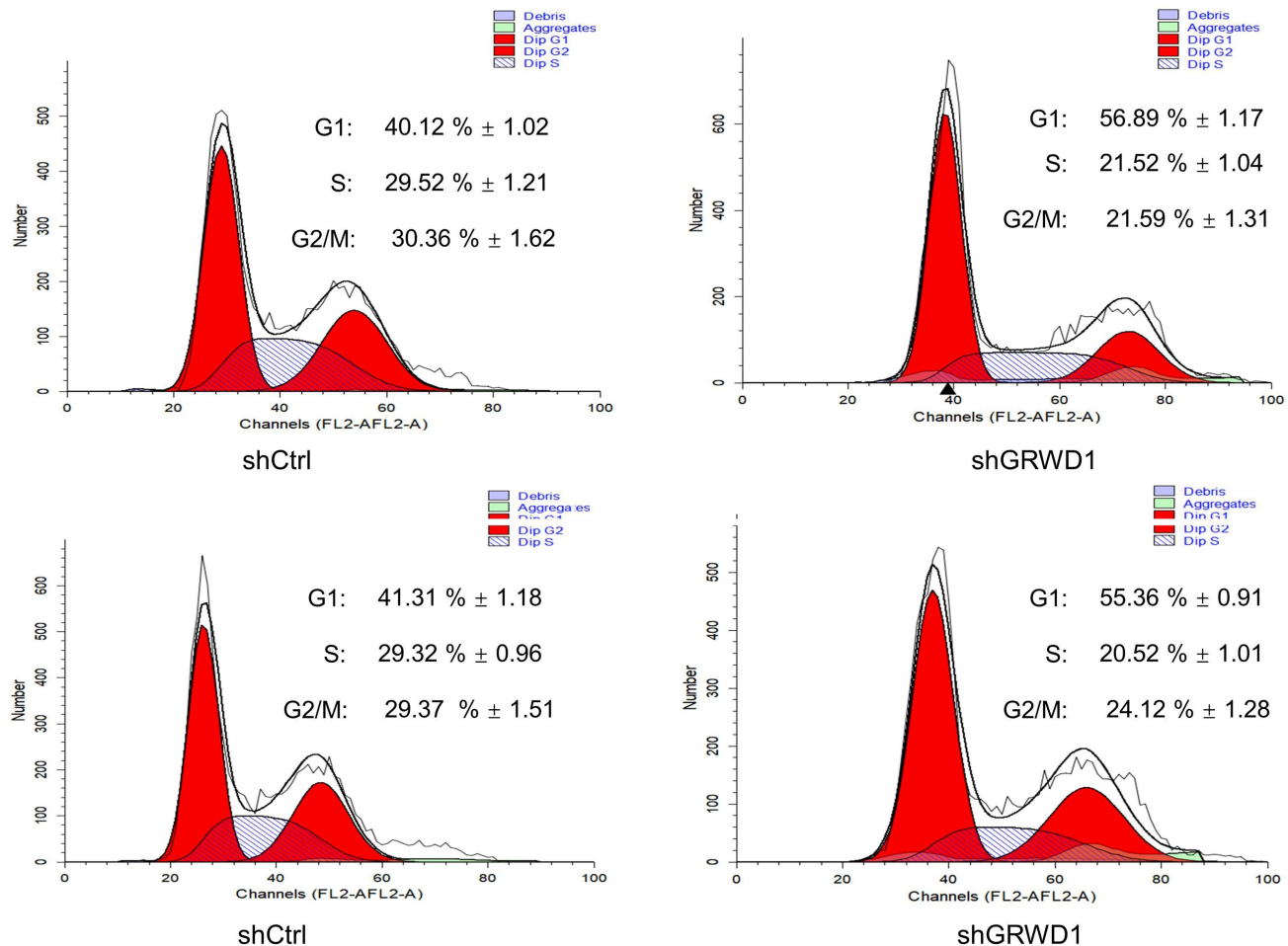

ShGRWD1

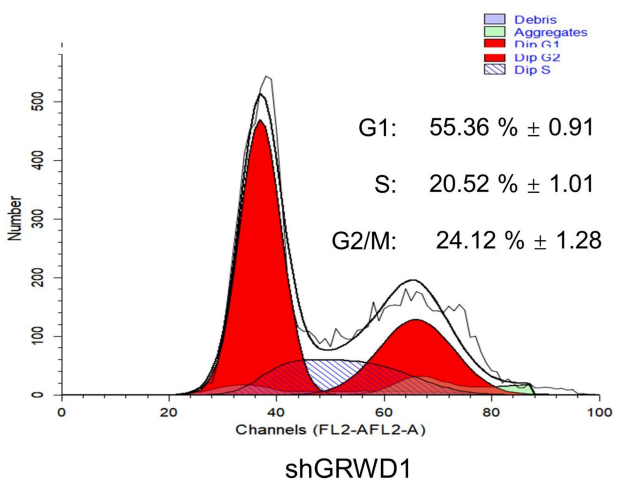

Figure 4 Effect of GRWDI knockdown on colony formation, DNA replication and cell cycle distribution. (A) Effect of GRWDI knockdown on cell colony formation. The numbers of shGRWDI colony were normalized with that of shCtrl (***P $<0.001)$. (B) The DNA synthesis of RKO cells detected by EdU assays. Hoechst staining indicated living cells, and EdU staining indicated the DNA molecule under duplicating. (C and D) Representative distributions of cell cycle phases of RKO cells and SW480 cells after GRWDI knockdown detected via flow cytometry. Data are expressed as mean \pm SD from three independent experiments. 
A

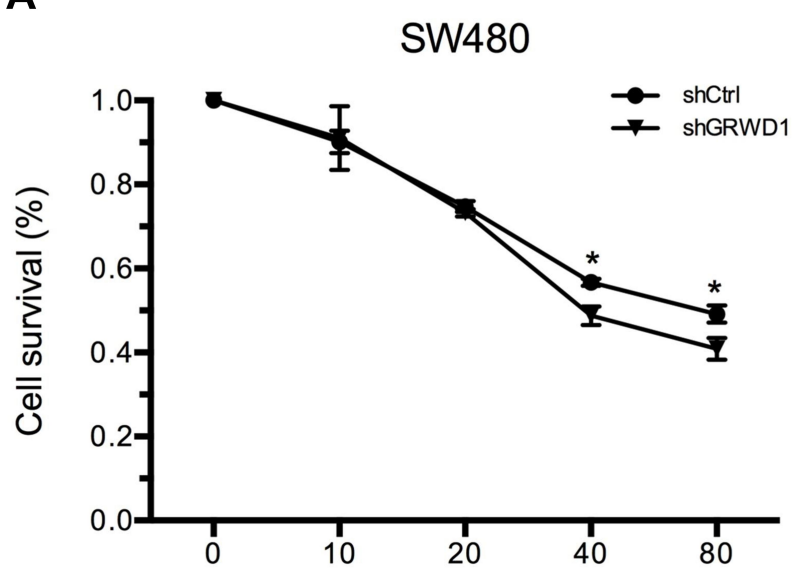

Concentration of LOHP $(\mu \mathrm{M})$

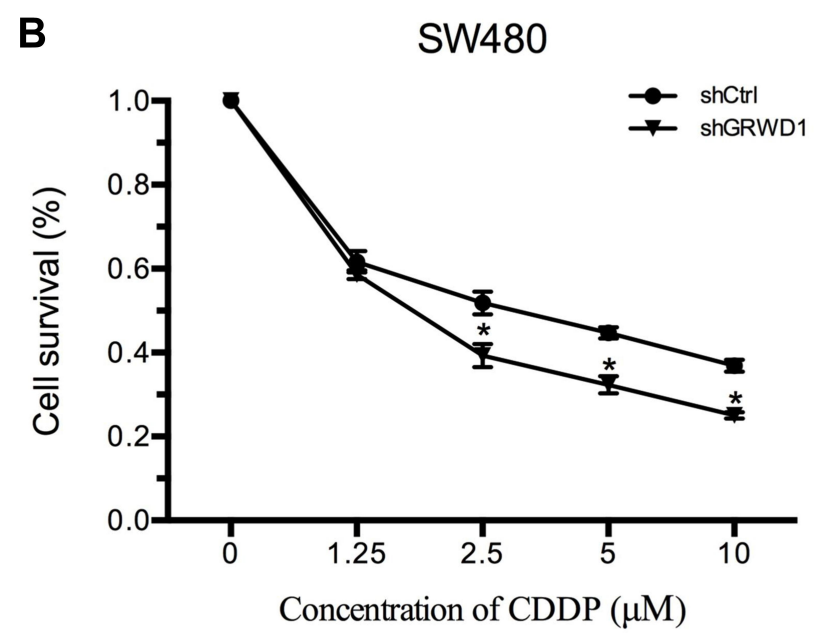

C

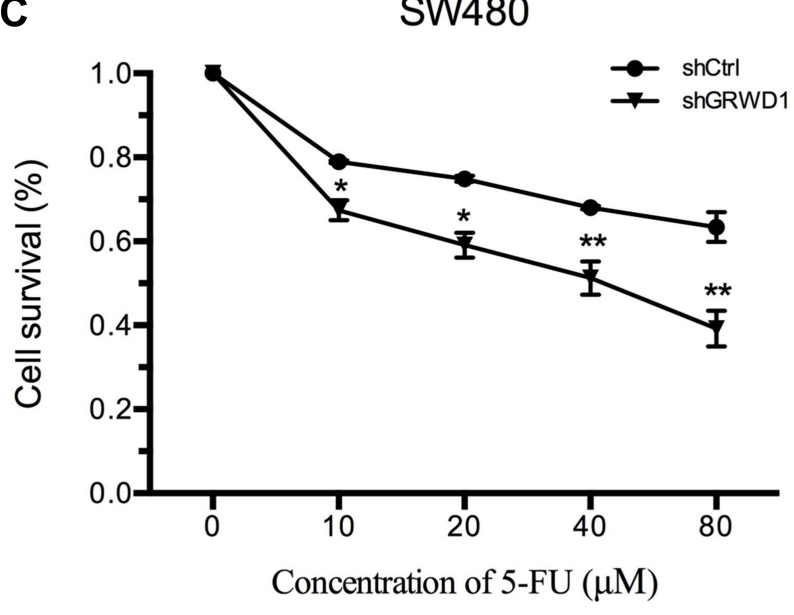

RKO
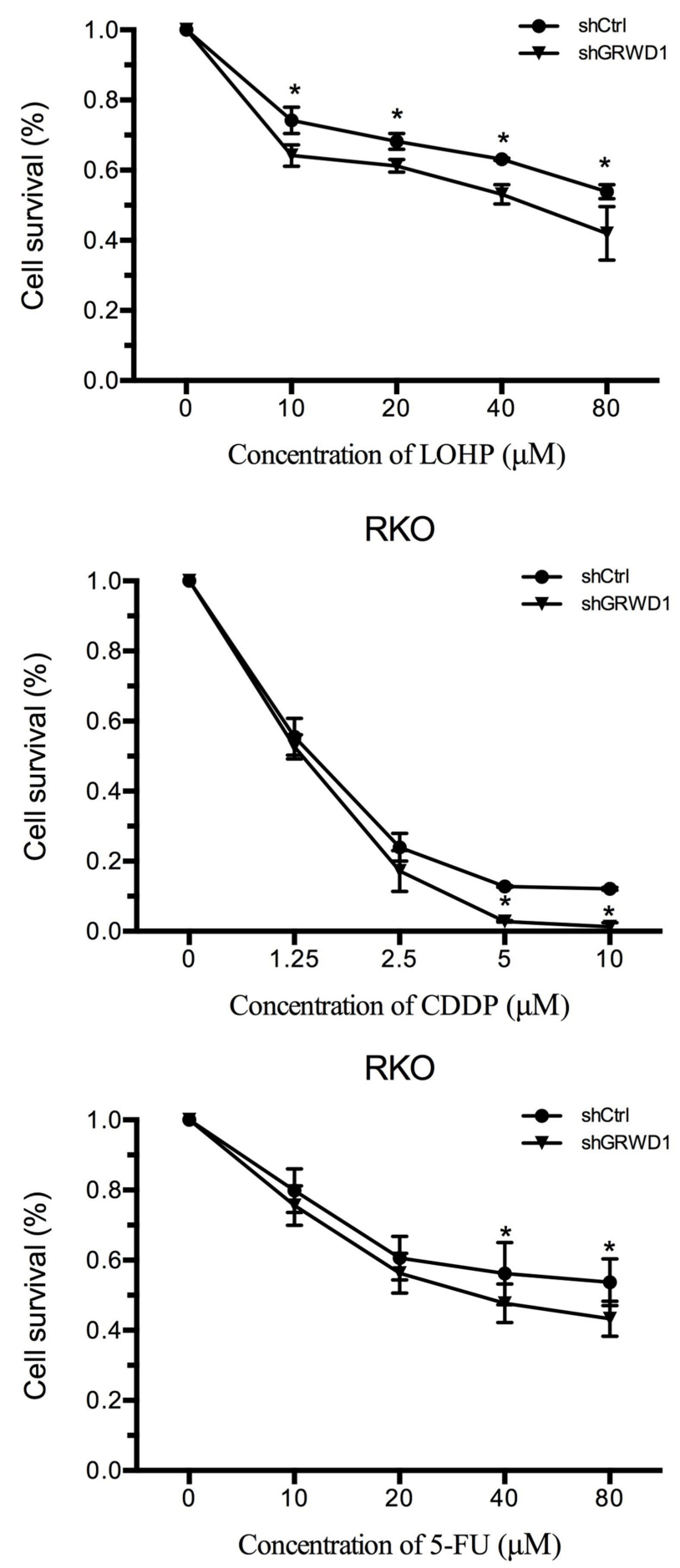

Figure 5 Effect of GRWDI knockdown on drug susceptibility. Cell viability of shCtrl or shGRWDI for SW480 and RKO cells detected by CCK8 assay. The line charts plot the drug susceptibility to $48 \mathrm{~h}$ treatment of different concentration of LOHP (A), CDDP (B), and 5-FU (C). *P $<0.05 ; * * P<0.01$. 
A
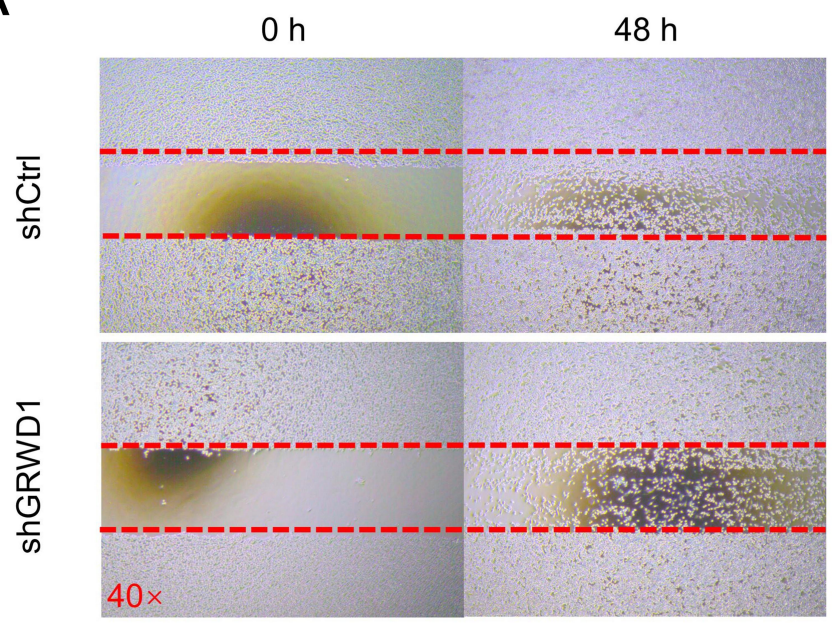

B

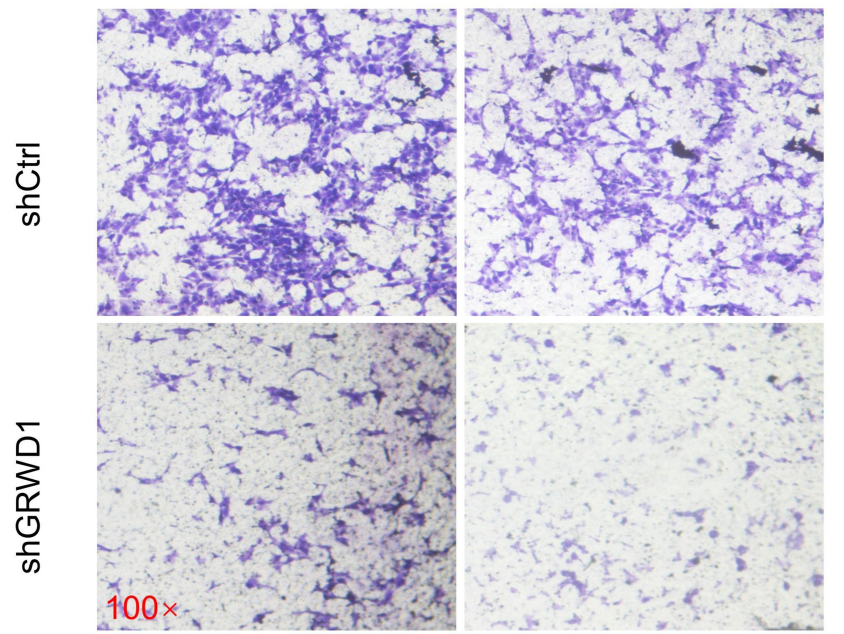

C

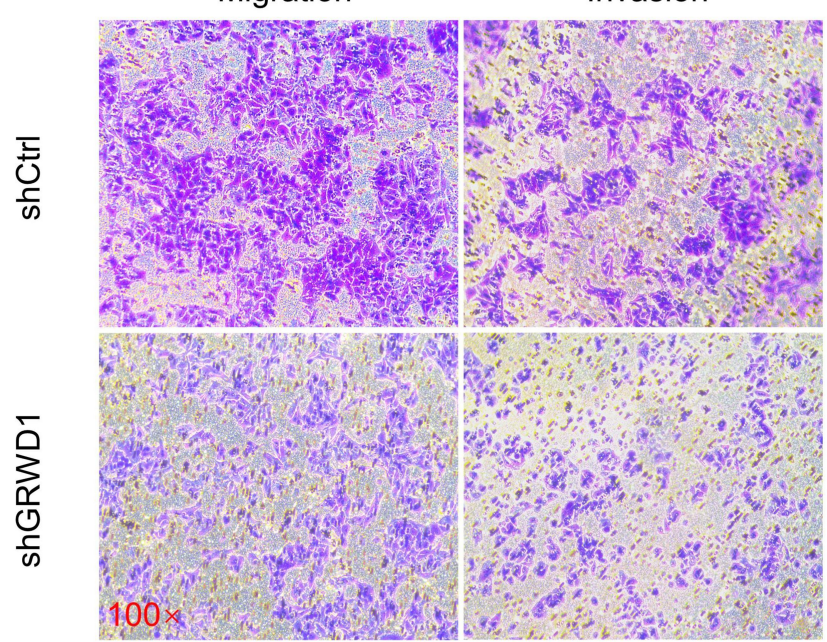

Migration

\section{RKO}

Invasion

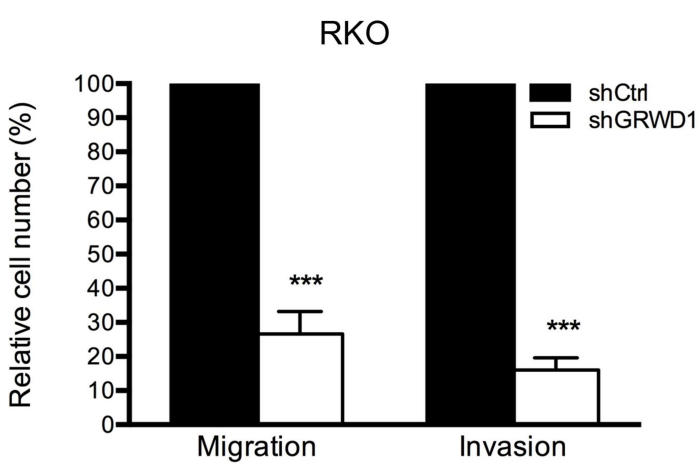

\section{SW480}

$\mathrm{Oh}$

$48 \mathrm{~h}$
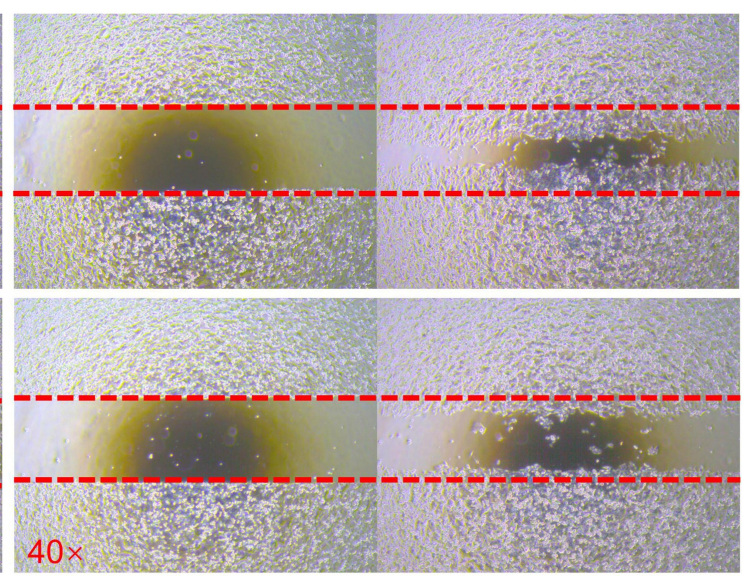

Migration

\section{SW480}

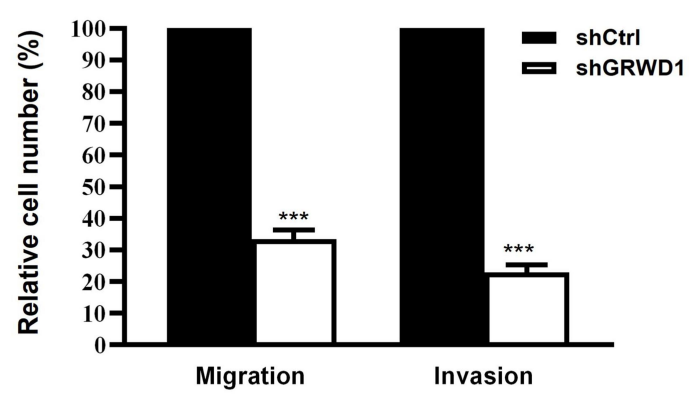

Figure 6 Effect of GRWDI knockdown on the migration and invasion of colon cancer cells. (A) Migration of RKO and SW480-shCtrl and -shGRWDI cells was detected by wound-healing assay after scratched with $200 \mu \mathrm{L}$ plastic pipette tip and cultured in serum-free medium for $48 \mathrm{~h}$. Pictures were photographed at 0 h and $48 \mathrm{~h}$. (B and $\mathbf{C}$ ) Migration and invasion of RKO and SW480 cells were respectively detected by transwell assays without and with Matrigel after GRWDI knockdown. Data are represented as the mean $\pm S D$ of three independent experiments. $* * * p<0.001$. 
promoting role in the migration and invasion of colon carcinoma cells.

\section{The Potential Mechanisms of GRWDI in Regulating the Development of Colon Carcinoma}

Those above results showed that GRWD1 played important roles in the proliferation, cell cycle, drug sensitivity, and migration and invasion of colon cancer cells. However, the potential mechanisms under the regulation of colon carcinoma development by GRWD1 need to be investigated. The primary analysis from online GEPIA database showed that GRWD1 expression was positively related to proliferation-related genes: PCNA and Ki67 (Figure 7A), cell cycle-related genes: Cyclin A2 and Cyclin B1 (Figure 7B), drug resistance-related genes: ABCC1 and GSTP1 (Figure 7C) and metastasis-related genes: MTA1 and MTA2 (Figure 7D).

Based on the above research results, we proposed a working model about the tumorigenic function of GRWD1. As a novel Cdt1-binding protein in MCM helicase complexes, ${ }^{14}$ GRWD1 upregulation promotes the combination with CDC6 and Cdt1, further increases MCM loading and induces DNA replication, and then activates the transcriptions of several tumorigenesisrelated genes (Figure 8)

\section{Discussion}

Our results revealed that GRWD1 was overexpressed in tissues of clinical CRC patients through the TCGA database and IHC analyses. GRWD1 upregulation was also correlated with several clinical- pathological factors including pathological grading, tumor size, $\mathrm{N}$ stage, and TNM stage. We constructed GRWD1 knockdown and overexpression CRC cell models to detect whether GRWD1 had effects on the development of CRC. We found that GRWD1 knockdown inhibited cell proliferation, on the contrary, the growth of CRC cells was promoted by GRWD1 overexpression. Besides, GRWD1 knockdown arrested cell cycle on the G1 phase, increased drug sensitivity, and reduced the ability of invasion and migration. From these results, we concluded that GRWD1 played an important role in tumorigenesis of colon carcinoma.

Many previous studies reported that incidence rates of CRC were increasing every year, especially among young people. ${ }^{15}$ Scientists dedicated to find the molecular mechanisms and possible therapeutic targets of cancer in the past few years, studies on potential genes that are evolved in colon carcinoma tumorigenesis may provide good prospects for diagnosis and therapy. ${ }^{16}$ Our study found GRWD1 was highly expressed in several cancers including breast carcinoma, lung squamous cell carcinoma, skin cutaneous melanoma, and also markedly evaluated in colon carcinoma. A recent study also showed that GRWD1 was highly expressed in non-small cell lung cancer (NSCLC). Besides, it could activate the Notch signaling pathway which induces cell proliferation in NSCLC. ${ }^{10}$ We also confirmed GRWD1 had a significant correlation with pathological grading, tumor size, and TNM stage. Although GRWD1 expression was not shown an obvious relationship with the overall rate of survival in all CRC patients, the overall survival rates of the months after surgery in all patients and patients with different clinical stages were shown significant relations with GRWD1 expression. These results further demonstrated that GRWD1 was an independent risk factor for poor development of colon carcinoma.

GRWD1, a WD-repeat-containing protein, is related to ribosome biosynthesis. GRWD1 overexpression is mainly localized in nuclear and slightly localized in cytoplasmic which is consistent with our findings. ${ }^{6}$ The IHC analysis was shown that GRWD1 was both expressed in nuclear and cytoplasmic while the staining intensity of GRWD1 in nuclear was higher than cytoplasmic. It was confirmed that GRWD1 was associated with p53. p53 is well known as a tumor suppresser and a transcriptional factor that regulates a series of genes expression including related genes of metabolic homeostasis, DNA repair, cell cycle, and DNA repair. ${ }^{17-19}$ Ubiquitin ligase MDM2 is involved in $\mathrm{p} 53$ degradation. ${ }^{20}$ Activated ribosomal proteins including RPL11 and RPL23 could interact with MDM2 and result in an accumulation of $\mathrm{p} 53 .{ }^{21}$ Therefore, $\mathrm{p} 53$ is reduced when GRWD1 overexpression. Besides the RPL11/ RPL23-MDM2-p53 axis, a recent study reported that GRWD1 is directly bound to the DNA-domain of p53 and negatively regulated $\mathrm{p} 53$ expression. ${ }^{7}$ All these results indicated that GRWD1 is a potential oncogene.

Our results showed that GRWD1 overexpression induced the growth in CRC cells in vitro and in vivo, while GRWD1 knockdown inhibited the colony formation and DNA replicate capacity. The expressions of proliferation-related genes: PCNA and ki67 were positively related to GRWD1 expression. These findings demonstrated that 


\section{A}
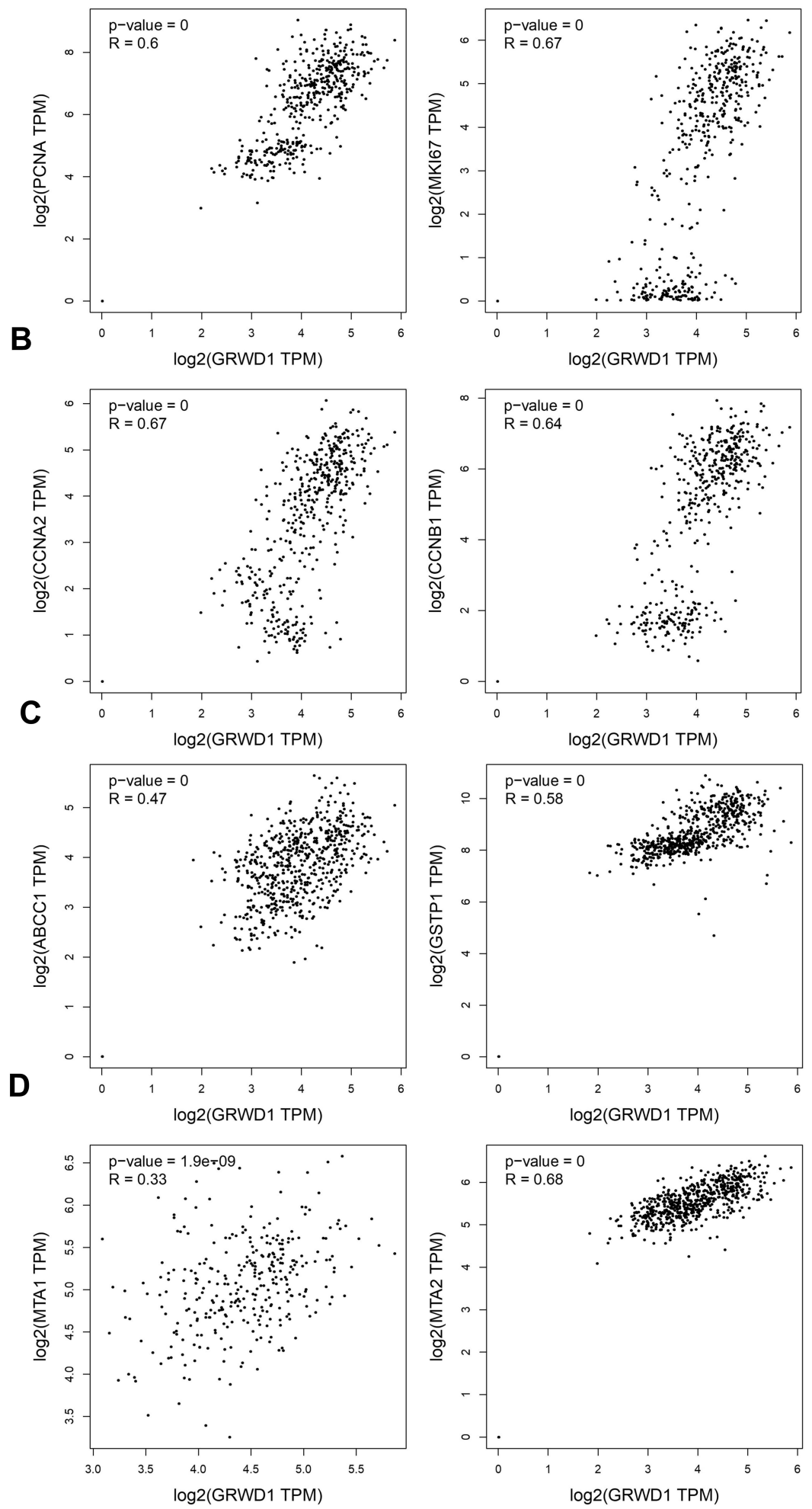

Figure 7 Correlation between the expression of GRWDI and several genes that are associated with the pathogenesis of colon cancer. The GEPIA online database was used to evaluate the correlations of GRWDI and proliferation-related genes (A), cell cycle-related genes (B), multidrug resistance-related genes (C), metastasis-related genes (D). Correlation was calculated using Spearman/Pearson correlation test. R value indicates the correlation coefficient. 

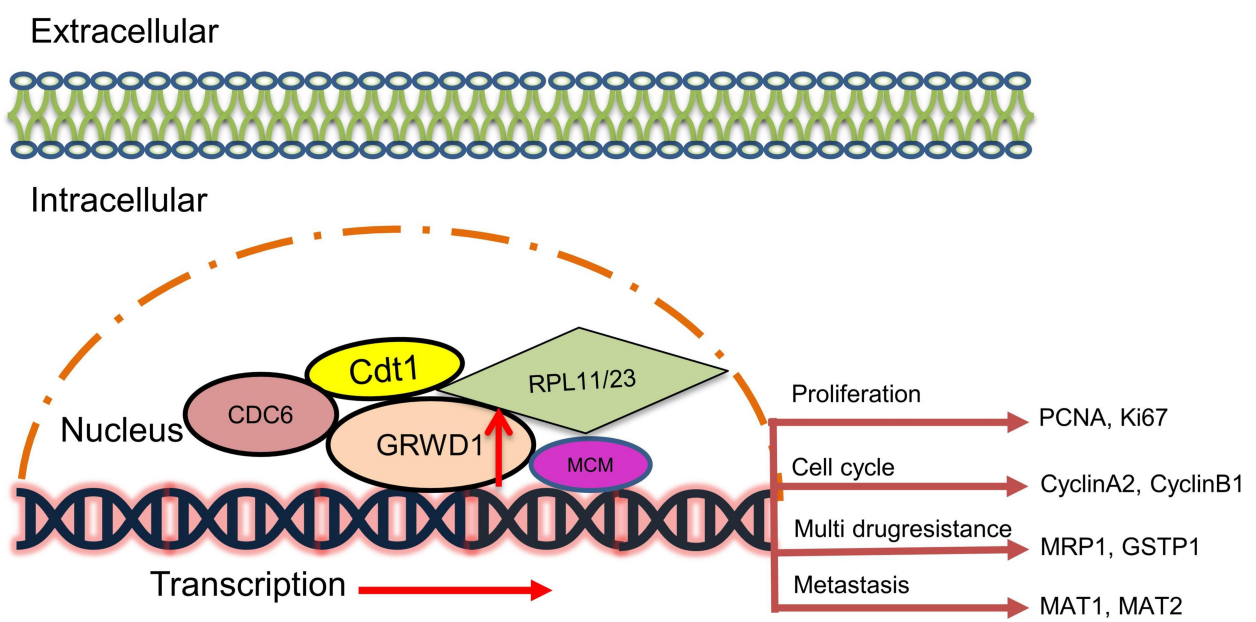

Figure 8 A predicted working model of GRWDI in regulating the progression of colon carcinoma. GRWDI may play as an oncogene through affecting the expression of various aspects of genes including proliferation, cell cycle, drug resistance and metastasis. (CDC6, cell division cycle 6; Cdt I, chromatin licensing and DNA replication factor I; RPLI I/23, ribosomal protein LII/23; MCM, minichromosome maintenance complex component).

GRWD1 indeed had a markable effect on cell proliferation.

We further analyzed the cell cycle after the GRWD1 knockdown. Previous studies showed that DNA replication is important for cell cycle. Pre-replication complex (pre-RC) contained CDC6, CDC1 and MCM helicase formation is one procedure of DNA replication. GRWD1 could interact with CDC6 and Cdt1, sequentially increase MCM loading and induce DNA replication. ${ }^{22}$ Our results indicated that GRWD1 knockdown arrested cell cycle at the G1 phase, and slighted increased $\mathrm{S}$ and G2/M phase which was consistent with the previous study. Cells of the G2/M phase were slightly increased after GRWD1 depletion. $^{22}$ We assessed the cell cycle-related genes: cyclin A2 and cyclin B1. Cyclin A2 was proved to be related with G1 and $\mathrm{S}$ phase, cyclin B1 inhibition caused G2/M phase arrest and increased cell growth. ${ }^{23,24}$ Both two genes had a significant correlation with GRWD1 expression. We still need to investigate the expression of cell-cycle related proteins after GRWD1 knockdown in further study.

Oxaliplatin (L-OHP), 5-fluorouracil (5-FU) and cisplatin (CDDP) are widely used in the treatment of colon carcinoma. A combination of different chemotherapy agents is an efficient treatment for cancer patients. Meanwhile, drug resistance also gradually occurs. ${ }^{25-27}$ In our study, we found that GRWD1 knockdown effectively increased the drug sensitivity in CRC cells. Moreover, the analyses between GRWD1 with MRP1 and GSTP1 showed a positive correlation. MRP1 belongs to the human multidrug resistance-associated protein (MRP) family. This membrane protein mainly results in clinical drug resistance. ${ }^{28,29}$ GSTP1 belongs to the glutathione Stransferase (GST) family. ${ }^{30}$ GSTP1 overexpression in cancer cells was found that it promoted the resistance to multiple drugs. ${ }^{31}$ Therefore, GRWD1 may be a potential therapeutic target in the treatment of colon carcinoma.

Metastasis is the main cause of cancer death and it is responsible for morbidity and mortality. ${ }^{32}$ Our study found that GRWD1 had a significant correlation with lymph node metastasis, besides GRWD1 knockdown inhibited the ability of migration and invasion of colon carcinoma cells. Analysis of GEPIA database showed that GRWD1 was related to metastasis-related genes: metastasis-associated gene 1 (MTA1) and metastasis-associated gene 2 (MTA2). MTA1, a transcriptional coregulator, played an important role in cancerous procedure. Many studies demonstrated that MTA1 overexpression facilitated invasion and migration in several cancer cells including laryngeal squamous cell carcinoma (LSCC), esophageal squamous cell carcinoma, and melanoma. ${ }^{33-35}$ MTA2 had a similar function with MTA1. Previous study also showed that MTA2 promoted the invasion of gastric cancer cells. ${ }^{36}$ In conclusion, GRWD1 had an important effect on invasion and migration in colon carcinoma cells.

Our study firstly confirmed GRWD1 promoted cell proliferation, drug resistance, cell cycle procedure, invasion and migration in colon carcinoma cells. We also put forward a potential mechanism of GRWD1 in oncogenesis. However, these predicted mechanisms of GRWD1 tumorpromoting functions are still unconfirmed. Therefore, we will next focus on these in further studies. 


\section{Funding}

This study was supported by the Science Foundation of the Fujian Province, (No. 2016J01602; 2019J0105), Special Financial Foundation of Fujian Provincial (No.20151297), Young and middle-aged backbone training project in the health system of Fujian province (2016-ZQN-26), the Startup Fund for Scientific Research, Fujian Medical University (2017XQ1029, 2018QH2027), and the Professor Development Foundation of Fujian Medical University (No.JS11006).

\section{Disclosure}

The authors declare that there are no competing interests.

\section{References}

1. Bray F, Ferlay J, Soerjomataram I, Siegel RL, Torre LA, Jemal A. Global cancer statistics 2018: GLOBOCAN estimates of incidence and mortality worldwide for 36 cancers in 185 countries. CA Cancer J Clin. 2018;68(6):394-424. doi:10.3322/caac.21492

2. Levine O, Zbuk K. Colorectal cancer in adolescents and young adults: defining a growing threat. Pediatr Blood Cancer. 2019;66 (11):e27941. doi:10.1002/pbc.27941

3. Bailey CE, Hu CY, You YN, et al. Increasing disparities in the agerelated incidences of colon and rectal cancers in the United States, 1975-2010. JAMA Surg. 2015;150(1):17-22. doi:10.1001/ jamasurg.2014.1756

4. Subramanian S, Amonkar MM, Hunt TL. Use of colonoscopy for colorectal cancer screening: evidence from the 2000 National Health Interview Survey. Cancer Epidemiol Biomarkers Prev. 2005;14 (2):409-416. doi:10.1158/1055-9965.EPI-03-0493

5. Li H, Chen YX, Wen JG, Zhou HH. Metastasis-associated in colon cancer 1: a promising biomarker for the metastasis and prognosis of colorectal cancer. Oncol Lett. 2017;14(4):3899-3908. doi:10.3892/ ol.2017.6670

6. Gratenstein K, Heggestad AD, Fortun J, Notterpek L, Pestov DG, Fletcher BS. The WD-repeat protein GRWD1: potential roles in myeloid differentiation and ribosome biogenesis. Genomics. 2005;85(6):762-773. doi:10.1016/j.ygeno.2005.02.010

7. Fujiyama H, Tsuji T, Hironaka K, Yoshida K, Sugimoto N, Fujita M. GRWD1 directly interacts with p53 and negatively regulates p53 transcriptional activity. J Biochem. 2020;167(1):15-24. doi:10.1093/ $\mathrm{jb} / \mathrm{mvz} 075$

8. Kayama K, Watanabe S, Takafuji T, et al. GRWD1 negatively regulates $\mathrm{p} 53$ via the RPL11-MDM2 pathway and promotes tumorigenesis. EMBO Rep. 2017;18(1):123-137. doi:10.15252/ embr.201642444

9. Takafuji T, Kayama K, Sugimoto N, Fujita M. GRWD1, a new player among oncogenesis-related ribosomal/nucleolar proteins. Cell Cycle 2017;16(15):1397-1403. doi:10.1080/15384101.2017.1338987

10. Wang Q, Ren $\mathrm{H}, \mathrm{Xu} \mathrm{Y}$, et al. GRWD1 promotes cell proliferation and migration in non-small cell lung cancer by activating the Notch pathway. Exp Cell Res. 2020;387(2):111806. doi:10.1016/j. yexcr.2019.111806

11. Deng X, Li S, Kong F, et al. Long noncoding RNA PiHL regulates p53 protein stability through GRWD1/RPL11/MDM2 axis in colorectal cancer. Theranostics. 2020;10(1):265-280. doi:10.7150/ thno. 36045

12. Dash BC, El-Deiry WS. Cell cycle checkpoint control mechanisms that can be disrupted in cancer. Methods Mol Biol. 2004;280:99-161. doi:10.1385/1-59259-788-2:099
13. Aparo S, Goel S. Evolvement of the treatment paradigm for metastatic colon cancer. From chemotherapy to targeted therapy. Crit Rev Oncol Hematol. 2012;83(1):47-58. doi:10.1016/j.critrevonc.20 11.08 .006

14. Aizawa M, Sugimoto N, Watanabe S, Yoshida K, Fujita M. Nucleosome assembly and disassembly activity of GRWD1, a novel Cdt1-binding protein that promotes pre-replication complex formation. Biochim Biophys Acta. 2016;1863(11):2739-2748. doi:10.1016/ j.bbamcr.2016.08.008

15. Puccini A, Lenz HJ, Marshall JL, et al. Impact of patient age on molecular alterations of left-sided colorectal tumors. Oncologist. 2019;24(3):319-326. doi:10.1634/theoncologist.2018-0117

16. Tomlinson I, Ilyas M, Novelli M. Molecular genetics of colon cancer. Cancer Metastasis Rev. 1997;16(1-2):67-79. doi:10.1023/ A:1005744323215

17. Vousden KH, Prives C. Blinded by the light: the growing complexity of p53. Cell. 2009;137(3):413-431. doi:10.1016/j.cell.2009.04.037

18. Riley T, Sontag E, Chen P, Levine A. Transcriptional control of human p53-regulated genes. Nat Rev Mol Cell Biol. 2008;9(5):402412. doi:10.1038/nrm2395

19. Levine AJ, Oren M. The first 30 years of p53: growing ever more complex. Nat Rev Cancer. 2009;9(10):749-758. doi:10.1038/nrc2723

20. Toledo F, Wahl GM. Regulating the p53 pathway: in vitro hypotheses, in vivo veritas. Nat Rev Cancer. 2006;6(12):909-923. doi: $10.1038 / \mathrm{nrc} 2012$

21. Zhang YP, Lu H. Signaling to p53: ribosomal proteins find their way. Cancer Cell. 2009;16(5):369-377. doi:10.1016/j.ccr.2009.09.024

22. Sugimoto N, Maehara K, Yoshida K, et al. Cdt1-binding protein GRWD1 is a novel histone-binding protein that facilitates MCM loading through its influence on chromatin architecture. Nucleic Acids Res. 2015;43(12):5898-5911. doi:10.1093/nar/gkv509

23. Yuan J, Kramer A, Matthess Y, et al. Stable gene silencing of cyclin B1 in tumor cells increases susceptibility to taxol and leads to growth arrest in vivo. Oncogene. 2006;25(12):1753-1762. doi:10.1038/sj. onc. 1209202

24. Pagano M, Pepperkok R, Verde F, Ansorge W, Draetta G. Cyclin-a is required at 2 points in the human cell-cycle. EMBO J. 1992;11 (3):961-971. doi:10.1002/j.1460-2075.1992.tb05135.x

25. Longley DB, Harkin DP, Johnston PG. 5-fluorouracil: mechanisms of action and clinical strategies. Nat Rev Cancer. 2003;3(5):330-338. doi:10.1038/nrc1074

26. Kim GP, Erlichman C. Oxaliplatin in the treatment of colorectal cancer. Expert Opin Drug Metab Toxicol. 2007;3(2):281-294. doi:10.1517/17425255.3.2.281

27. Kohno K, Wang KY, Takahashi M, et al. Mitochondrial transcription factor A and mitochondrial genome as molecular targets for cisplatinbased cancer chemotherapy. Int J Mol Sci. 2015;16(8):19836-19850. doi:10.3390/ijms160819836

28. Ishikawa T, Kuo MT, Furuta K, Suzuki M. The human multidrug resistance-associated protein (MRP) gene family: from biological function to drug molecular design. Clin Chem Lab Med. 2000;38 (9):893-897. doi:10.1515/CCLM.2000.130

29. Borst P, Evers R, Kool M, Wijnholds J. A family of drug transporters: the multidrug resistance-associated proteins. J Natl Cancer I. 2000;92 (16):1295-1302. doi:10.1093/jnci/92.16.1295

30. Tew KD. Glutathione-associated enzymes in anticancer drug-resistance. Cancer Res. 1994;54(16):4313-4320.

31. Townsend DM, Shen HX, Staros AL, Gate L, Tew KD. Efficacy of a glutathione S-transferase pi-activated prodrug in platinum-resistant ovarian cancer. Mol Cancer Ther. 2002;1(12):1089-1095.

32. Guan X. Cancer metastases: challenges and opportunities. Acta Pharm Sin B. 2015;5(5):402-418. doi:10.1016/j.apsb.2015.07.005

33. Zhang $\mathrm{H}$, Yang $\mathrm{D}$, Wang $\mathrm{H}$, et al. Metastasis-associated gene 1 promotes invasion and migration potential of laryngeal squamous cell carcinoma cells. Oncol Lett. 2014;7(2):399-404. doi:10.3892/ ol.2013.1729 
34. Qian H, Lu N, Xue L, et al. Reduced MTA1 expression by RNAi inhibits in vitro invasion and migration of esophageal squamous cell carcinoma cell line. Clin Exp Metastasis. 2005;22(8):653-662. doi:10.1007/s10585-006-9005-2

35. Qian $\mathrm{H}, \mathrm{Yu}$ J, Li Y, et al. RNA interference of metastasis-associated gene 1 inhibits metastasis of B16F10 melanoma cells in a C57BL/6 mouse model. Biol Cell. 2007;99(10):573-581. doi:10.1042/ BC20060130
36. Zhou C, Ji J, Cai Q, et al. MTA2 promotes gastric cancer cells invasion and is transcriptionally regulated by Sp1. Mol Cancer. 2013;12(1):102. doi:10.1186/1476-4598-12-102

\section{Publish your work in this journal}

OncoTargets and Therapy is an international, peer-reviewed, open access journal focusing on the pathological basis of all cancers, potential targets for therapy and treatment protocols employed to improve the management of cancer patients. The journal also focuses on the impact of management programs and new therapeutic

Submit your manuscript here: https://www.dovepress.com/oncotargets-and-therapy-journal agents and protocols on patient perspectives such as quality of life, adherence and satisfaction. The manuscript management system is completely online and includes a very quick and fair peer-review system, which is all easy to use. Visit http://www.dovepress.com/ testimonials.php to read real quotes from published authors. 